\title{
ORNITHOLOGY
}

\section{The Genius of Birds}

By Jennifer Ackerman. 2016. Penguin Random House. 340 pages, 23.00 CAD, Paper.

From its striking cover to its detailed index, Jennifer Ackerman delivers a wellcrafted popular science book to satisfy enthusiastic birders and armchair naturalists alike. The book is divided into eight chapters plus an Introduction, each with amusing titles such as "Four - Twitter: Social Savvy" and "Three - Boffins: Technical Wizardry". Each chapter features a delightful

illustration by John Burgoyne picking up on one of the stories or central themes of the chapter; these are excellent additions to the text and follow through on the promise of the Western Scrub Jay cover art by Eunike Nugroho.

As you might expect, much of the content is reasonably cerebral - the short subsections belie their content, and for most folks this will not be a book for drowsy before-bedtime reading. Fortunately, Jennifer Ackerman writes with a rich style that makes cognitive neuroscience research appealing and accessible. Through direct quotes and anecdotes curated from researcher interviews coupled with her own extensive research, the author explores various forms of avian intelligenceproblem solving, navigational, musical, and more.

This is a book full of surprises and unknowns, including cutting edge research as well as unanswered questions about common and rare species alike. Not limited to probing accounts of experimental research,
The Genius of Birds is full of cocktail conversation starters. I learned that pigeons are better at intuiting the Monty Hall Dilemma than I am, for example. And that some birds have a keen sense of smell, and may use it to navigate. This is not to say that this volume is just a litany of facts, nor that it strays from its central theme. The book is specialized in its focus: bird learning and intelligence are front and centre. The last chapter is the only one that delves into the 'big issues' of biodiversity declines, habitat loss, and climate change in a significant way.

The book is also exquisitely researched and has the largest reference list I've seen in a popular science book, with a whopping 54 pages of notes in reduced font size. If you would like more information on a particular topic and have journal subscription privileges, you will not be disappointed. If you forget where in the 266 content pages you read an interesting tidbit, there is also a detailed index so you can retrace your steps.

If you start the first page of The Genius of Birds thinking that birds are simple automatons incapable of logic or reasoning, you are in for a shock. If you came in already believing that birds are intelligent beings, you will turn the last page astounded by just how true that really is. I recommend this book to anyone looking for an in-depth read on bird intelligence, who wants to understand more about our feathered friends, and perhaps as a gift to friends and family members who don't understand why birdwatching is such a popular pastime.

HEATHER A. CRAY

Waterloo, ON, Canada 